\title{
Additive manufacturing in medical sciences: past, present and the future
}

\author{
Lakshya P. Rathore ${ }^{1 *}$, Naina Verma ${ }^{2}$ \\ ${ }^{1}$ Department of Orthopaedics, ${ }^{2}$ Department of of Otorhinolaryngology, SLBS GMCH, Himachal Pradesh, India
}

Received: 28 September 2018

Revised: 13 November 2018

Accepted: 15 November 2018

*Correspondence:

Dr. Lakshya P. Rathore,

E-mail: dr.lakshya.rathore@gmail.com

Copyright: (c) the author(s), publisher and licensee Medip Academy. This is an open-access article distributed under the terms of the Creative Commons Attribution Non-Commercial License, which permits unrestricted non-commercial use, distribution, and reproduction in any medium, provided the original work is properly cited.

\begin{abstract}
Additive manufacturing (AM) is a novel technique that despite having been around for more than 35 years, has been underutilized. Its great advantage lies in the basic fact that it is incredibly customizable. Since its use was recognized in various fields of medicine like orthopaedics, otorhinolaryngology, ophthalmology etc, it has proved to be one of the most promising developments in most of them. Customizable orthotics, prosthetics and patient specific implants and tracheal splints are few of its advantages. And in the future too, the combination of tissue engineering with AM is believed to produce an immense change in biological tissue replacement.
\end{abstract}

Keywords: Additive manufacturing, Tissue engineering, 3D printing, Bioink

\section{INTRODUCTION}

The term additive manufacturing (AM) or layered manufacturing covers a host of processes and technologies that offer a full spectrum of capabilities for the production of parts and products in different materials. ${ }^{1}$ The term $3 \mathrm{D}$ printing is often used as a synonym for AM, mostly in a non-technical context. Essentially, what all of the processes and technologies have in common is the manner in which production is carried out, layer by layer in an additive process, which is in contrast to traditional methods of production involving subtractive methods or moulding/casting processes. ${ }^{2,3}$

\section{HISTORY}

The origins of 3D printing can be traced back to 1986 , when the first patent was issued for stereolithography apparatus (SLA) from 3D systems, a process that solidifies thin layers of ultraviolet (UV) light-sensitive liquid polymer using a laser. ${ }^{4}$ This patent belonged to one
Charles Hull, who first invented his SLA machine in 1983 and the first use in healthcare industry was reported in 1999. However, this process was first described in 1981 by Hideo Kodama of Nagoya Municipal Industrial Research Institute when he invented manufacturing methods to create a $3 \mathrm{D}$ plastic model. ${ }^{5,6}$

It has a wide range of use in fields like aviation, automotive, sculpture, jewelry, architecture, food, pharmacology, medicine etc. Advantages include personalization and customizability, it is tool less, creates less waste, maximum utilization of resources, onsite production and many more. ${ }^{7,8}$ In medicine, it is considerably used in the fields of orthopedic surgery, maxillofacial oral surgery, otorhinolaryngology etc.

\section{PROCESS}

The first step in this process is acquiring the data which is done via CT scan, MRI or the PET- Scan. These 2D images are converted into $3 \mathrm{D}$ model by using software 
program like CAD/CAM (computer aided design) which the printer processes and prints by laying down the biomaterial in successive layers which fuse together to form a complete assembly., ${ }^{9,10}$

There are basically two techniques used for 3D printing. Either the biomaterial is extruded out by the printer and deposited layer by layer sequentially and simultaneously cured by UV light or, the printer onto a vat containing liquid polymer or resin, which hardens precisely where the laser hits it, focuses the laser. ${ }^{11}$ The vat then moves down by a sub-mm fraction and the next layer is created. This is repeated until the entire product is formed. ${ }^{12,13}$ There are a variety of materials used in 3D printing including PVA, titanium, steel, wax, ceramics, polycarbonate, nylon and bioink.

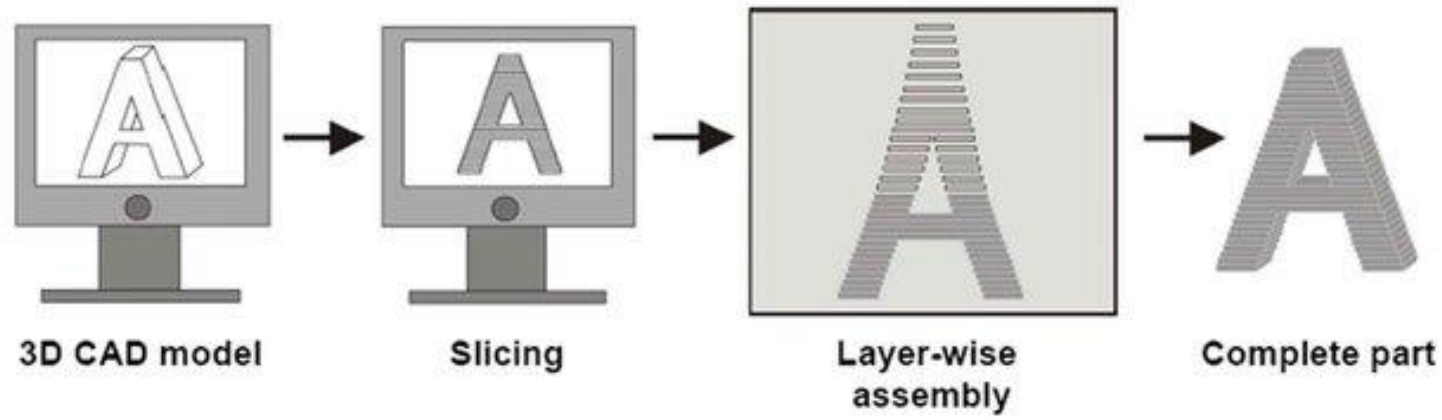

Figure 1: A simple flowchart showing the crude steps involved in the process of additive manufacturing.

\section{APPLICATIONS IN MEDICAL FIELD}

The uses of 3D printing are as wide as our imagination. It can be potentially used in any medical field and its use has greatly increased in surgical field since 2013. The applications in surgery can be broadly divided into:

- Anatomic models for teaching purpose and presurgery planning

- Implants, prosthesis, splints and external fixators

- Surgical instruments

- Biocompatible materials for tissue engineering and subsequent replacement of their biologic counterparts.

\section{ORTHOPAEDICS}

Patient education and counselling: 3D models created via additive manufacturing can help in making the patient and attendants more aware of what is exactly going to happen during the surgery and what the expectations are after the surgery. ${ }^{14}$

Surgical planning: the surgeon can create a 3D model of the fracture pattern itself and plan the surgery more meticulously with custom intraoperative guides as has been shown by study done by Bizzotto et al and Zhang et al. ${ }^{15,16}$

Implants and prosthesis: Triply periodic minimal surface (TPMS) structures have already been shown to be a versatile source of biomorphic scaffold designs. The titanium based 3D models have been shown to have good manufacturability and mechanical properties. They also had near accurate orthogonal orientation. ${ }^{17}$ Also the biomorphic designs created via ALM using titanium had stiffness comparable to human bone and thus they can be a promising material for load bearing implants. ${ }^{18,19}$

Reduced surgical time: Renson et al 3D modelled the fractured bone or the opposite normal bone in case of a comminuted fracture. ${ }^{20}$ On top of that you can ascertain a bioprinted titanium nail of exact length and girth along with accurate screw length. Tack et al too showed reduced surgical tiem in spinal surgery. ${ }^{21}$ Imagine yourself going into the OT with that knowledge, imagine the surgeon's confidence. It's like taking an open book test, the only difference being you know what the answer is.

Osteotomy: Using the patient specific (PS) blocks created by AM have shown better accuracy in correction along with decreased need of radiation exposure. ${ }^{22}$

Tumour resection: PS guides have proved to increase the accuracy and ease the procedure of resection of tumours of the tibia and the pelvis with tumour free margins. ${ }^{23,24}$

Orthotics: What makes 3D printing so interesting-and so downright fascinating - is that it allows individuals and companies of all sizes to create parts and objects that might not be possible at all otherwise. ${ }^{25}$

Prosthetics: As the skin plays a vital role in shaping our interactions with the world, stretchable electronic devices simulating the properties of skin could have far-reaching implications for prosthetics and medicine. ${ }^{26,27}$ Providing prosthetic hands with the ability to sense is particularly 
important, as each year $\approx 185000$ Americans suffer from limb loss, requiring substitutional prosthetics. ${ }^{28}$

\section{OPHTHALMOLOGY}

3D printing has been used for reconstructing shattered orbits after a high velocity injury. The crafted 3D models allow near normal orbital reconstruction and accurate reduction of fracture. The implants required can be customized and shaped according to site and extent of fracture. 3D printing can be used for making customizable instruments example trocar cannula system for vitreo-retinal surgery. In anophthalmoses, computer aided 3D prosthesis can been designed and manufactured. It can used to design scaffold for human trabecular meshwork (HTM) for studying the pathogenesis of glaucoma. AM enthusiasts manufactured a fully operating 3D printed porous HTM and treated it with prednisolone. The model suggested increased ECM production, decreased HTM cell phagocytosis, and decreased the outflow resistance as present in steroid induced glaucoma. ${ }^{29,30,31,48}$

3D models of eye can be created to plan stereotactic radiosurgery in carcinomas for optimal and accurate irradiation with minimal side effects. Hong et al have recently described a $3 \mathrm{D}$ printable device for imaging of retina that is compatible for use with a smart phone to capture an image of the retina. ${ }^{32}$

\section{OTORHINOLARYNGOLOGY AND HEAD AND NECK SURGERY}

Apart from creating custom anatomical models, AM has also found application in auricular reconstruction with a highly realistic 3D printed auricular prosthesis and hearing aids. ${ }^{33,34}$ Others are championing the use of AM in craniofacial reconstruction and managing the paediatric airway in severe tracheobronchomalacia. ${ }^{35,36}$

\section{OTHER FIELDS}

AM has become the most sought research field in various other medical sciences like cardiothoracic surgery, urology, plastic surgery, gastrointestinal surgery and dentistry etc. ${ }^{17,37-41}$

\section{ADVANTAGES}

3D printing, whether at an industrial, local or personal level, enables a host of gains that conventional methods of manufacturing (or prototyping) do not.

Less waste: since additive process and not subtractive where about $80-90 \%$ material was being lost.

Less running cost: in the long run, when production will reach a certain level, the total cost would be much less. Also AM does not require fixtures or molds or tooling in producing which reduces cost by upto $25 \%$.
Limitless: complex shapes that could not be manufactured in any other way are possible with this process since it can internally build support structures for overhangs and undercuts.

Wide range: a wide range of materials maybe used to make an array of products according to requirements.

Customisation: Notwithstanding, within the same construction cell, 3D printing amounts to the advantage that multiple products can be constructed at the same time as per the demand at no additional processiing cost.

Tool-less: eliminate the need for tool production and, therefore, the costs, lead times and labour associated with it.

Sustainable / environment friendly: 3D printing is also emerging as an energy-efficient technology that can provide environmental efficiencies.

Zero lead time: building the final shape can begin as soon as the designing process is initiated.

Onsite production: the prints can be taken and used at the site of requirement.

Test models: 3D printing allows for testing of smaller versions of the original design before investing in a larger manufacturing program.

Shortens the duration of surgery, hence decreases anaesthesia exposure and blood loss.

Biocompatible: less chance of tissue rejection. Biocompatible materials are assessed in terms divisions related to medical licensing, cytotoxicity, hypersensitivity reaction and when the building materials are biocompatible, the final product will be too.

\section{FUTURE}

Recent advances include 3D bioprinting, which combines tissue engineering with $3 \mathrm{D}$ printing, which has led to an explosion of research within various fields in biotechnology and medicine. ${ }^{42} 3 \mathrm{D}$ bioprinting involves depositing cells or biomaterials on a biocompatible scaffold in layers where the cell viability and functions are preserved. As of now it is still in early phase but the option of making a functional replacement of tissues is very intriguing indeed. The main limiting factor here is the vascularization because the synthesis of any tissue which is more than 200 micron thick requires adequate perfusion that has not been achieved yet in vivo. ${ }^{43}$ While some have been able to construct scaffolds of bone and cartilaginous elements for bony and osteochondral defects, still there is much to be done in this area. ${ }^{44,45}$

Bioink is a dense cellular slurry of water based liquid containing cells or enzymes or proteins and the sourcing 
of cells and their viability on 3D printed scaffolds is not exactly known yet. ${ }^{46}$ Along with that, the growth factors required in the process are very costly and they have shown reduction in effects in situ. ${ }^{43}$

With many more obstacles to overcome, it can be said reliably that additive manufacturing is a promising field and it has the ability to extend the horizons of various medical sciences. Although AM is no substitute of the experience and expertise of the surgeon, but the day is not far when the patient will be operated upon by a robot who will be knowing the exact implant along with the exact place where to put the screws in. Who knows there might come a day that we won't need someone to donate organs, we would be getting them readymade. In this battle of hope vs hype only the future holds the answer.

\section{Funding: No funding sources}

Conflict of interest: None declared

Ethical approval: Not required

\section{REFERENCES}

1. Mohammad T, Prashant KJ. Role of build orientation in layered manufacturing: a review. Int J Manufacturing Tech Management. 2013;27:1-3.

2. Chhaya MP, Poh PS, Balmayor ER, van Griensven M, Schantz JT, Hutmacher DW. Additive manufacturing in biomedical sciences and the need for definitions and norms. Expert Rev Med Devices. 2015;12(5):537-43.

3. Schmid M, Amado A, Wegener K. Materials perspective of polymers for additive manufacturing with selective laser sintering. J Mater Res. 2014;29:1824-32.

4. Terry W, Tim G. History of additive manufacturing. Wohlers Report; 2014: 36-78.

5. Kodama H. Automatic method for fabricating a three-dimensional plastic model with photohardening polymer. Rev Sci Instrum. 1981;52(11):1770-3.

6. Kodama H. A scheme for three-dimensional display by automatic fabrication of three-dimensional model. IEICE Trans Electron Jpn Ed. 1981;J64-C (4): $237-241$.

7. Murphy SV, Atala A. 3D bioprinting of tissues and organs. Nat Biotechnol. 2014;32(8):773-85.

8. Zhu W, Ma X, Gou M, Mei D, Zhang K, Chen S. $3 \mathrm{D}$ printing of functional biomaterials for tissue engineering. Curr Opin Biotechnol. 2016;40:103-12.

9. Cummins. The rise of additive manufacturing. The engineer. Available at: http://www.theengineer. co.uk/issues/24-may-2010/the-riseof- additivemanufacturing/. Accessed 20 July 2018.

10. Rengier F, Mehndiratta A, von Tengg-Kobligk H, Zechmann CM, Unterhinninghofen R, Kauczor HU, et al. 3D printing based on imaging data: review of medical applications. Int $\mathrm{J}$ Comput Assist Radiol Surg. 2010;5(4):335-41.
11. Wengerter BC, Emre G, Park JY, Geibel J. Threedimensional printing in the intestine. Clin Gastroenterol Hepatol. 2016;14:1081-5.

12. Mironov V, Boland T, Trusk T, Forgacs G, Markwald RR. Organ printing: computer-aided jetbased 3D tissue engineering. Trends Biotechnol. 2003;21:157-61.

13. Sun W, Lal P. Recent development on computer aided tissue engineering: a review. Comput. Methods Programs Biomed. 2002;67:85-103.

14.

15. Sanghera B, Naique S, Papaharilaou Y, Amis A. Preliminary study of rapid prototype medical models. Rapid Prototyping J. 2001;7:275-84.

16. Bizzotto N, Tami I, Santucci A, Adani R, Poggi P, Romani D, et al. 3D printed replica of articular fractures for surgical planning and patient consent: a two years multicenter experience. 3D Print Med. 2015;2:2.

17. Zhang YZ, Chen B, Lu S, Yang Y, Zhao JM, Liu R, et al. Preliminary application of computer assisted patient-specific acetabular navigational template for total hip arthroplasty in adult single developmental dysplasia of hip. Int J Med Robot. 2011;7:469-74.

18. Tunchel S, Blay A, Kolerman R, Mijiritsky E, Shibli JA. 3D Printing/Additive Manufacturing Single Titanium Dental Implants: A Prospective Multicenter Study with 3 Years of Follow-Up. Int J Dent. 2016;2016:8590971.

19. Murr LE, Gaytan SM, Medina F, Lopez H, Martinez E, Machado BI, et al. Next generation biomedical implants using additive manufacturing of complex, cellular and functional mesh arrays. Philos Trans A Math Phys Eng Sci. 2010;368:1999-2032.

20. Vaezi M, Black C, Gibbs DM, Oreffo RO, Brady M, Moshrefi-Torbati M, et al. Characterization of new PEEK/HA composites with 3D HA network fabricated by extrusion freeforming. Molecules 2016;21(6):E687.

21. Renson L, Poilvache P, Van den Wyngaert H. Improved alignment and operating room efficiency with patient specific instrumentation for TKA. Knee. 2014;21:1216-20.

22. Tack P, Victor J, Gemmel P, Annemans L. 3Dprinted techniques in a medical setting: a systematic literature review. Biomed Eng Online. 2016;15:115.

23. Victor J, Premanathan A. virtual 3D planning and patient specific surgical guides for osteotomies around the knee: a feasibility and proof-of-concept study. Bone Joint J. 2013;95-B (Suppl A):153-8.

24. Bellanova L, Paul L, Docquier PL. Surgical guides (patient specific instruments) for paediatric tibial bone sarcoma resection and allograft reconstruction. Sarcoma. 2013;2013:787653.

25. Gouin F, Paul L, Odri GA, Cartiaux O. Computer assisted planning and patient specific instruments for bone tumor resection within the pelvis: a series of 11 patients. Sarcoma. 2014;2014:842709.

26. Natalia W, Filip Górski, Radosław W, Wiesław K. Prototyping of Individual Ankle Orthosis Using 
Additive Manufacturing Technologies. Adv Sci Technol Res J. 2017;11(3):283-8.

27. Stephen PH, Adam W, Anson WK Ma. Prosthesis Development Utilizing Additive Manufacturing and Low-Cost Electronics. 10.13140/RG.2.2.24564. 65923. Available at: https://www.researchgate.net/ publication/319834536_Prosthesis_Development_U tilizing_Additive_Manufacturing_and_Low-

Cost_Electronics. Accessed on 20 July 2018.

28. Mills DK. Future Medicine: The Impact of 3D Printing. Nanomater Mol Nanotechnol. 2015;4(3):1000163.

29. Guo S-Z, Qiu K, Meng F, Park SH, McAlpine MC. 3D Printed Stretchable Tactile Sensors. Adv Mat. 2017:29(27):1701218.

30. Mawale MB, Kuthe A, Pawane P, Dahake SW, Jyotilal S. Development of a Device in Detection of Glaucoma for Rural Eye Care Using Additive Manufacturing and TRIZ. Molecular Cellular Biomechanics. 2016;13(2):105-14.

31. Ju Y, Wang BL, Xie JZ, Huang LW, Huang SH, Huang XY. Dynamic model of the aqueous humor circulation with application to simulation of the treatment for primary open angle glaucoma. Proceedings of the IEEE Engineering in Medicine and Biology 27th Annual Conference Shanghai. 2005;1:15-18.

32. Hitchings RA. Glaucoma: an area of darkness. Eye. 2009;23:1764-1774.

33. Sheng CH. 3D Printing and Ophthalmology for the Community. J Cytol Histol. 2015;6:4.

34. Suaste-Gomez E, Rodríguez-Roldan G, Reyes-Cruz $\mathrm{H}$, Teran-Jimenez O. Developing an ear prosthesis fabricated in polyvinylidene fluoride by a $3 \mathrm{D}$ printer with sensory intrinsic properties of pressure and temperature. Sensors. 2016;16(332):1-11.

35. Sharma R. The 3D printing revolution you have not heard about, Forbes. 2013: 17e16.

36. https://www.forbes.com/sites/rakeshsharma/2013/07 /08/the-3d-printing-revolution-you-have-not-heardabout/\#2f87bf441a6b. Accessed on 20 July 2018.

37. Choi JW, Kim N. Clinical application of threedimensional printing technology in craniofacial plastic surgery. Arch Plast Surg. 2015;42(3):267-77.

38. Zopf DA, Hollister SJ, Nelson ME, Ohye RG, Green GE. Bioresorbable airway splint created with a three-dimensional printer. $\mathrm{N}$ Engl $\mathrm{J}$ Med. 2013;368:2043-5.
39. Díaz Lantada A, Valle-Fernández RD, Morgado PL, Muñoz-García J, Muñoz Sanz JL, Munoz-Guijosa JM, et al. Development of persoanlised annuloplasty rings: comination of $\mathrm{CT}$ images and CAD-CAM tools. Ann Biomed Eng. 2010;38:280-90.

40. Sodian R, Haeberie S, Weber S. Medical rapid prototyping (MRP) in adult and paediatric cardiac surgery. Thoracic Cardiovasc Surg. 2011;59:P15.

41. Stone J, Candela B, Alleluia V, Fazili A, Richards M, Feng C, et al. A novel technique for simulated surgical procedures using 3D printed technology. J Urol. 2015;193(suppl):270.

42. Xu Y, Fan F, Kang N, et al. Tissue engineering of human nasal alar cartilage precisely by using threedimensional printing. Plast Reconstr Surg. 2015;135:451-8.

43. Watson RA. A low cost surgical application of additive fabrication. J Surg Educ. 2014;71:14-7.

44. Zhu W, Ma X, Gou M, Mei D, Zhang K, Chen S. $3 \mathrm{D}$ printing of functional biomaterials for tissue engineering. Curr Opin Biotechnol. 2016;40:103112.

45. Gibbs DMR, Vaezi M, Yang S, Oreffo RO. Hope versus hype : what can additive manufacturing realistically offer treauma and orthoapedic surgery? Regen Med. 2014;9:835-49.

46. Bian W, Li D, Lian Q, Jin Z. Fabrication of a bioinspired beta-Tricalcium phosphate/collagen scaffold based on ceramic sterolithography and gel casting for osteochondral tissue engineering. Rapid Prototyping J. 2012;18:68-80.

47. Du Y, Liu H, Shuang J, Wang J, Ma J, Zhang S. microsphere based selective sintering for building macroporous bone scaffolds with controlled microstructure and excellent biocompatibility. Colloids Surf B Biointerfaces. 2015;135:81-9.

48. Murphy SV, Atala A. 3D bioprinting of tissues and organs. Nat Biotechnol. 2014;32:773-785.

49. Huang W, Zhang X. 3D Printing: Print the future of ophthalmology. Invest Ophthalmol Vis Sci. 2014;55(8):5380-1.

Cite this article as: Rathore LP, Verma N. Additive manufacturing in medical sciences: past, present and the future. Int J Res Orthop 2019;5:201-5. 